\title{
Evaluation of Measurement Accuracy of the MEMS Accelerometer for Long Period and Large Amplitude Vibration
}

\author{
Kenta Hirai ${ }^{1, ~ a ~}{ }^{*}$, Hiroaki Harada1, b, Hirotaka Imaeda1, c , Akira Mita², d \\ Takeshi Suzuki, e, Hironobu Yao ${ }^{3, \text { f , Shinji Kitagawa }}{ }^{3, g}$ \\ Minoru Kakinuma ${ }^{3, h}$, Yoshiyuki Komiya ${ }^{4, i}$ \\ ${ }^{1}$ Structural Engineering Section, NIKKEN SEKKEI LTD, Tokyo, Japan \\ ${ }^{2}$ Keio University, Kanagawa, Japan \\ ${ }^{3}$ Fuji Electric Co., LTD, Tokyo, Japan \\ ${ }^{4}$ Hakusan Corporation, Tokyo, Japan \\ ahirai.kenta@nikken.jp, bharadah@nikken.jp, cimaedah@nikken.jp, ${ }^{d}$ mita@keio.jp \\ esuzuki-takeshi@fujielectric.com, fyao-hironobu@fujielectric.com, 9kitagawa-shinji@fujielectric.com \\ hkakinuma-minoru@fujielectric.com, iyoshiyuki.komiya@hakusan.co.jp
}

\section{Keywords: MEMS Accelerometer, Monitoring System, Measurement Accuracy}

\begin{abstract}
Health monitoring systems are used to assess building damage immediately after an earthquake and have become widely utilized in Japan. For example, the system developed by the authors has been installed in more than 60 buildings since 2014. Such systems mostly rely on accelerometers to estimate the building performance. Recently, Micro electro mechanical system (MEMS) accelerometers have been increasingly applied for such uses due to their economic advantages. However, MEMS accelerometers are known to have relatively low measurement accuracy for certain frequency band excitations compared to servo type accelerometers. Past research has been undertaken to test their measurement accuracy, however, few studies review their performance under long period and large amplitude seismic motions. Evaluation of measurement accuracy in such conditions is essential since the system is also installed in tall buildings and isolated buildings with relatively long natural periods. Therefore, this study evaluates the measurement accuracy of the MEMS accelerometer under long period and large amplitude vibration based on the results of shake table testing.
\end{abstract}

\section{Introduction}

In recent years large earthquakes have occurred relatively often in Japan, and many more people are interested in building safety. From a Business Continuity Plan (BCP) perspective, the monitoring system have been widely utilized to help assess damage immediately after an earthquake. The authors developed a health monitoring system using accelerometers in 2014 . This system has been installed in more than 60 buildings and the validity of the system has been verified (Ishizaki, Imaeda, Harada, Shinohara, 2018).

The monitoring system is also installed in high-rise buildings and isolated buildings with relatively long natural periods. In this condition, the accuracy of accelerometer measurement for long period and large amplitude vibrations is important. Recently, Micro electro mechanical system (MEMS) accelerometers have been increasingly applied for monitoring systems due to their economic advantages. However, MEMS accelerometers are known to have relatively low measurement accuracy for certain frequency band excitations compared to servo type accelerometers. Although past research has been undertaken to test the measurement accuracy of 
MEMS accelerometers, few studies review their performance under long period and large amplitude seismic motions. This study evaluates the measurement accuracy of the MEMS accelerometer under long period and large amplitude vibration based on the results of shake table testing.

\section{Methods}

The experiment equipment comprises a shaking table and eight accelerometers. The shaking table used is a linear motor active mass damper produced by IHI Infrastructure Systems Co., Ltd. These dampers are usually installed in tall buildings to provide supplementary damping, but were chosen for this test setup because they can simulate long period and large amplitude vibration with high accuracy. Table 1 shows the specifications of accelerometers used in this test. Five accelerometers (id101-103 and SU202-2, SU202-3) are MEMS accelerometers and one (SU501-1) is a servo type accelerometer. The servo type sensor $(\mathrm{K} 1, \mathrm{~K} 2)$ was used as reference accelerometer. The eight accelerometers were installed as shown in figure 2.

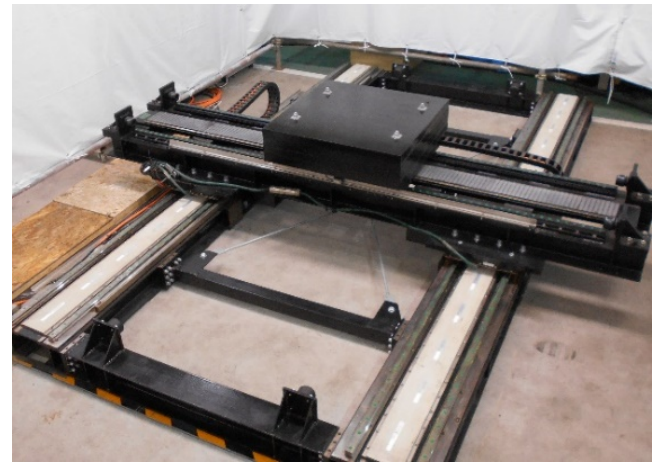

Figure 1: Linear motor active mass damper ${ }^{[3]}$

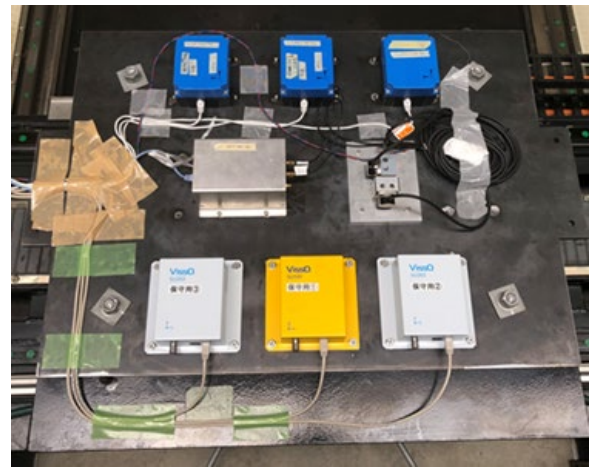

Figure 2: Installation setup of the sensors

Table 1: Accelerometer specifications

\begin{tabular}{|c|c|c|c|c|}
\hline Sensor name & id101,id102,id103 & SU501-1 & SU202-2, SU202-3 & $\begin{array}{c}\mathrm{K} 1, \mathrm{~K} 2 \\
\text { (reference accelerometer) }\end{array}$ \\
\hline Type & MEMS & Servo & MEMS & Servo \\
\hline Freaquency range & $0.1 \sim 50 \mathrm{~Hz}$ & $\mathrm{DC} \sim 30 \mathrm{~Hz}$ & $\mathrm{DC} \sim 50 \mathrm{~Hz}$ & $\mathrm{DC} \sim 500 \mathrm{~Hz}$ \\
\hline Number of channels & 3 channnels & 3 channnels & 3 channnels & 1 channnel \\
\hline Measuring range & $\pm 2 \mathrm{G}$ & $\pm 4 \mathrm{G}$ & $\pm 2 \mathrm{G}$ & $\pm 2 \mathrm{G} / \pm 4 \mathrm{G}$ \\
\hline
\end{tabular}

Eighteen cases were tested (Table 2). Sine waves and simulated earthquake motion were employed as inputs of the shake table testing. Measurement accuracy was assessed with several frequency cases and amplitude cases to detect frequency dependence and amplitude dependence. Ten waves are provided for one set. In total, 10 sets are implemented to evaluate the measurement accuracy. Simulated earthquake motion were used to evaluate measurement accuracy for actual building response. Tall buildings and isolated buildings were assumed in this test. 
Table 2: Shaking table test cases

\begin{tabular}{|c|c|c|c|c|c|}
\hline No & Direction & $\begin{array}{c}\text { Freaquency } \\
{\left[\begin{array}{c}\mathrm{Hz}]\end{array}\right.}\end{array}$ & $\begin{array}{l}\text { Period } \\
\text { [sec] }\end{array}$ & $\begin{array}{c}\text { Amplitude } \\
{[\mathrm{m}]}\end{array}$ & Number of analyzes \\
\hline 1 & $x$ & 0.10 & 10 & \multirow{6}{*}{1.00} & 10 \\
\hline 2 & $Y$ & 0.10 & 10 & & 10 \\
\hline 3 & $x$ & 0.13 & 8 & & 10 \\
\hline 4 & $\bar{Y}$ & 0.13 & 8 & & 10 \\
\hline 5 & $x$ & 0.17 & 6 & & 10 \\
\hline 6 & $\mathrm{Y}$ & 0.17 & 6 & & 10 \\
\hline 7 & $\mathrm{x}$ & 0.17 & 6 & \multirow{4}{*}{0.60} & 10 \\
\hline 8 & $\mathrm{Y}$ & 0.17 & 6 & & 10 \\
\hline 9 & $\mathrm{X}$ & 0.25 & 4 & & 10 \\
\hline 10 & $\mathrm{Y}$ & 0.25 & 4 & & 10 \\
\hline 11 & $x$ & 0.17 & 6 & \multirow{4}{*}{0.40} & 10 \\
\hline 12 & $\bar{Y}$ & 0.17 & 6 & & 10 \\
\hline 13 & $\mathrm{X}$ & 0.25 & 4 & & 10 \\
\hline 14 & $\mathrm{Y}$ & 0.25 & 4 & & 10 \\
\hline $15-1$ & $x$ & \multicolumn{2}{|c|}{$\begin{array}{l}\text { Simulated earthquake motion } \\
\text { (isolated buildings) }\end{array}$} & 0.20 & 1 \\
\hline $15-2$ & $x$ & \multicolumn{2}{|c|}{$\begin{array}{l}\text { Simulated earthquake motion } \\
\text { (isolated buildings) }\end{array}$} & 0.40 & 1 \\
\hline $16-1$ & $x$ & \multicolumn{2}{|c|}{$\begin{array}{l}\text { Simulated earthquake motion } \\
\text { (tall buildings) }\end{array}$} & 0.35 & 1 \\
\hline $16-2$ & $x$ & \multicolumn{2}{|c|}{$\begin{array}{l}\text { Simulated earthquake motion } \\
\text { (tall buildings) }\end{array}$} & 0.70 & 1 \\
\hline
\end{tabular}

\section{Shaking table test results}

\section{Measurement accuracy for accelerometers}

Since the raw data of the shake table tests includes noise in high and low frequency range, data treatment using Band-pass filter (BPF) is usually required to remove the influence of noise. Figure 3 shows specifications of the BPF. Also, Hanning windows were applied to remove the influence of disordered vibration observed at the beginning and end of the waveform because of the shake table characteristics.

Evaluation of measurement accuracy for acceleration was performed as follows;

1. Apply the Hanning window function to remove the influence of the beginning and end of the waveform

2. Apply Fourier transform

3. Apply BPF to remove the influence of high and low frequencies noise

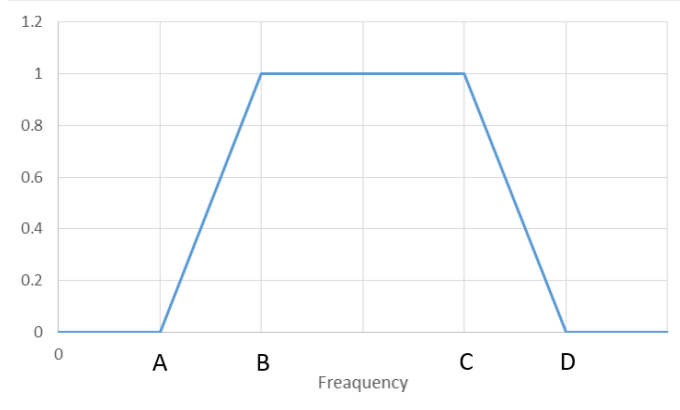

\begin{tabular}{|c|c|c|c|c|}
\hline \multirow{2}{*}{$\begin{array}{c}\text { Natural period of } \\
\text { target wave } \\
{[\mathrm{sec}]}\end{array}$} & \multicolumn{4}{|c|}{ Cut off Freaquency [Hz] } \\
\cline { 2 - 5 } & $\mathrm{A}$ & $\mathrm{B}$ & $\mathrm{C}$ & $\mathrm{D}$ \\
\hline $6 \leqq \mathrm{~T}$ & 0.1 & 0.125 & 25 & 27 \\
\hline $6>\mathrm{T}$ & 0.04 & 0.05 & 25 & 27 \\
\hline
\end{tabular}

Figure 3: The specification of $B P F$ 


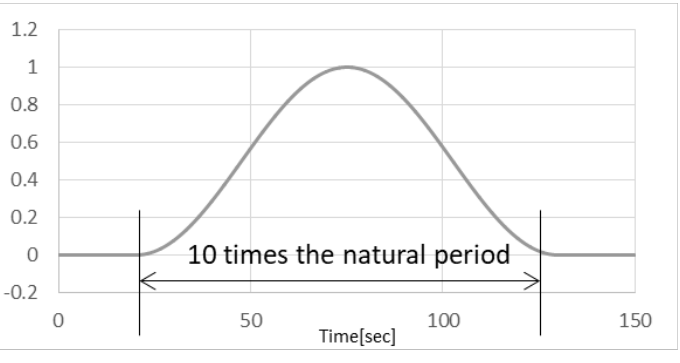

a) The Hanning window function

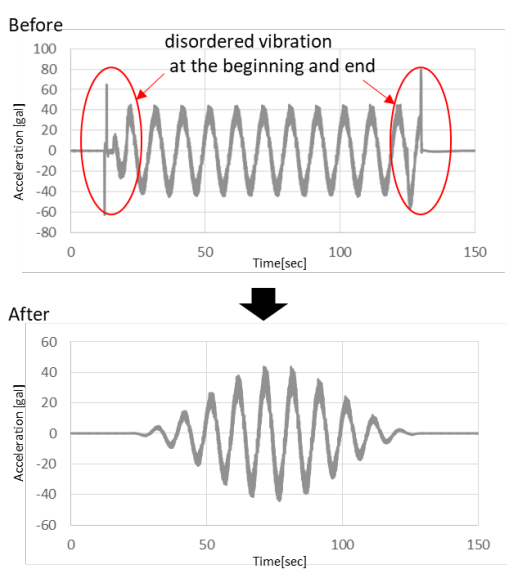

b) Remove the influence of disorder at start and end

Figure 4: The data processed by The Hanning window function

The measurement accuracy of the acceleration is evaluated by using the ratio of the maximum value of the acceleration Fourier spectrum to the reference. The data from the reference accelerometer is used as a reference. First, the ratio for each of the 10 waves in one set of the experiment was calculated. Second, the mean value of the ratio of the 10 waves was determined. Then, the mean and standard deviations of the 10 sets of experiements were calculated. Table 3 shows the mean and standard deviations of the ratios of the maximum acceleration values of the Fourier spectrum in each test case. The average of the maximum values is no less than 0.975 in all cases. Also, the standard deviations show low values, no more than 0.0002537 . These results indicate that the MEMS acceleration sensor can have almost the same measurement accuracy as the reference accelerometer. Additionally, no particular difference is observed between the test cases for the $\mathrm{X}$ direction and $\mathrm{Y}$ direction. This result suggests that there is no sensitivity of the measurement accuracy to direction of excitation.

Figure 5 shows the relationship between the frequency and the mean acceleration maximum value ratios. There appears to be no remarkable relationship although the variation tends to become somewhat larger at low frequencies. Figure 6 shows the relationship between the amplitude and the mean acceleration maximum value ratios.

No remarkable relationship was observed between the amplitude and the measurement accuracy, although the variation tends to slightly increase as the amplitude increases. Given these results, it has been confirmed that the MEMS acceleration sensor can accurately measure the acceleration even for a large amplitude vibrations of $1 \mathrm{~m}$ and vibration periods of 10 seconds.

Table 3: Mean and standard deviations of the ratios of the maximum acceleration values

\begin{tabular}{|c|c|c|c|c|c|c|c|c|c|c|c|c|c|c|c|}
\hline \multirow{2}{*}{$\begin{array}{l}\text { Case } \\
\text { No. }\end{array}$} & \multirow{2}{*}{$\begin{array}{c}\text { Amplitude } \\
{[\mathrm{cm}]}\end{array}$} & \multirow{2}{*}{$\begin{array}{c}\text { Freaquency } \\
{[\mathrm{Hz}]}\end{array}$} & \multirow{2}{*}{ Direction } & \multicolumn{2}{|c|}{ id101 } & \multicolumn{2}{|c|}{ id102 } & \multicolumn{2}{|c|}{ id103 } & \multicolumn{2}{|c|}{ SU501-1 } & \multicolumn{2}{|c|}{ SU202-2 } & \multicolumn{2}{|c|}{ SU202-3 } \\
\hline & & & & mean & Deviation & mean & Deviation & mean & Deviation & mean & Deviation & mean & Deviation & mean & Deviation \\
\hline 1 & 100 & 0.10 & $\bar{x}$ & 0.9893 & $1.579 \mathrm{E}-04$ & 0.9874 & $2.442 \mathrm{E}-05$ & 0.9892 & $1.953 \mathrm{E}-05$ & 0.9963 & $5.900 \mathrm{E}-05$ & 0.9862 & $6.587 \mathrm{E}-05$ & 1.0102 & $8.205 \mathrm{E}-05$ \\
\hline 2 & & & $\frac{\bar{Y}}{Y}$ & 9760 & $2.021 \mathrm{E}-04$ & 0.9771 & $1.563 \mathrm{E}-05$ & 0.9782 & $2.224 \mathrm{E}-05$ & 1.0135 & $1.469 \mathrm{E}-05$ & 0.9858 & $2.535 \mathrm{E}-05$ & 0.9946 & $3.324 \mathrm{E}-05$ \\
\hline 3 & & & $\bar{x}$ & 19890 & $2.537 \mathrm{E}-04$ & 0.9873 & $3.986 \mathrm{E}-05$ & 0.9892 & $4.036 \mathrm{E}-05$ & 0.9962 & $4.400 \mathrm{E}-05$ & 0.9862 & $4.270 \mathrm{E}-05$ & 1.0102 & $5.604 \mathrm{E}-05$ \\
\hline 4 & & & & & & 0.9772 & $\mathrm{E}-05$ & 0.9782 & $2.233 \mathrm{E}-05$ & & & & & 0.9945 & $5.602 \mathrm{E}-05$ \\
\hline 5 & & & $x$ & 0.9895 & $8.425 \mathrm{E}-05$ & 0.9877 & $3.746 \mathrm{E}-05$ & 0.9895 & $3.373 \mathrm{E}-05$ & 0.9962 & $3.041 \mathrm{E}-05$ & 0.9862 & $3.526 \mathrm{E}-05$ & 1.0102 & $3.717 \mathrm{E}-05$ \\
\hline 6 & & & & & $2.285 \mathrm{E}-04$ & 0.9776 & $3.980 \mathrm{E}-05$ & 0.9787 & $3.873 \mathrm{E}-05$ & & $1.351 \mathrm{E}-05$ & & $2.969 \mathrm{E}-05$ & 0.9945 & $1.589 \mathrm{E}-05$ \\
\hline 7 & & & & 9893 & $5.084 \mathrm{E}-05$ & 0.9875 & $2.375 \mathrm{E}-05$ & 0.9894 & $2.192 \mathrm{E}-05$ & 0.9962 & $3 \mathrm{E}-05$ & 0.9862 & $3.314 \mathrm{E}-05$ & 1.0102 & $2.158 \mathrm{E}-05$ \\
\hline 8 & 60 & & $\hat{\mathrm{Y}}$ & 0.9761 & $6.675 \mathrm{E}-05$ & 0.9775 & $1.925 \mathrm{E}-05$ & 0.9786 & $1.934 \mathrm{E}-05$ & 1.0135 & $8.924 \mathrm{E}-06$ & 0.9858 & $4.518 \mathrm{E}-05$ & 0.9946 & $2.071 \mathrm{E}-05$ \\
\hline 9 & & & & & & & & & $3.341 \mathrm{E}-05$ & & $9.673 \mathrm{E}-06$ & & $1.673 \mathrm{E}-05$ & 1.0102 & $1.514 \mathrm{E}-05$ \\
\hline 10 & & & & 9767 & -05 & 0.9781 & E-05 & 0.9792 & 3E-05 & & $3 E-06$ & 858 & $3 \mathrm{E}-05$ & 0.9946 & $1.523 \mathrm{E}-05$ \\
\hline 11 & 40 & & $x$ & 0.9891 & $7.571 \mathrm{E}-05$ & 0.9872 & $3.858 \mathrm{E}-05$ & 0.9891 & $4.089 \mathrm{E}-05$ & 0.9963 & $9 \mathrm{E}-05$ & 0.9861 & $4.811 \mathrm{E}-05$ & 1.0102 & $5.528 \mathrm{E}-05$ \\
\hline 12 & & & & & $6.462 \mathrm{E}-05$ & 0.9770 & \begin{tabular}{c|}
$.0052 \mathrm{E}-06$ \\
$.052 \mathrm{C}$
\end{tabular} & & $4.528 \mathrm{E}-06$ & & & & $\frac{4.0177 \mathrm{E}-05}{6.177}$ & 0.9946 & $\frac{0.020 L}{6.198 \mathrm{E}-05}$ \\
\hline 13 & 40 & & $x$ & 0.9894 & $1.715 \mathrm{E}-04$ & 0.9876 & $2.119 \mathrm{E}-05$ & 0.9894 & $2.409 \mathrm{E}-05$ & 0.9962 & $9 \mathrm{E}-06$ & 0.9862 & $2.024 \mathrm{E}-05$ & 1.0102 & $1.931 \mathrm{E}-05$ \\
\hline 14 & 40 & 0.25 & $\bar{Y}$ & 0.9761 & $7.376 \mathrm{E}-05$ & 0.9775 & $9.610 \mathrm{E}-06$ & 0.9786 & $1.450 \mathrm{E}-05$ & 1.0135 & $5.446 \mathrm{E}-06$ & 0.9858 & $1.488 \mathrm{E}-05$ & 0.9946 & $2.801 \mathrm{E}-05$ \\
\hline
\end{tabular}




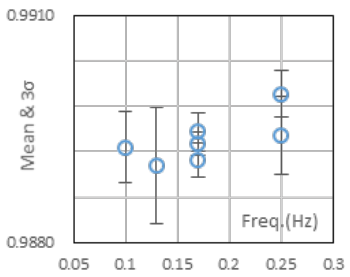

a) id 101

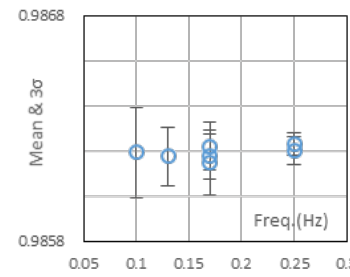

b) SU202-2

Figure 5: The relationship between the frequency and the measurement accuracy (Direction X)

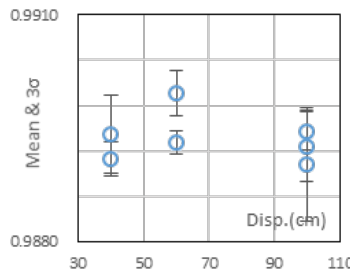

a) id 101

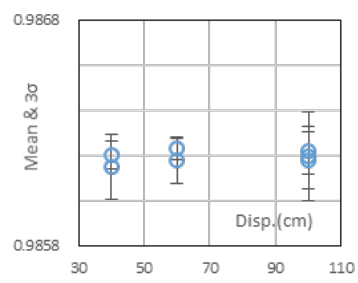

b) SU202-2
Figure 6: The relationship between the amplitude and the measurement accuracy (Direction X)

Measurements accuracy for displacement

BPF was also applied for the evaluation of measurement accuracy for the displacement to remove the influence of high and low frequency noise. The specification of the BPF is the same as the one used for the evaluation of measurement accuracy for acceleration (figure 3). Then, the displacement is calculated by the second integral and the inverse Fourier transform.

Evaluation of measurement accuracy for displacement is performed as follows;

1. Apply Fourier transform

2. Apply BPF to remove the influence of high and low frequency noise

3. Convert to displacement data by second-order integration

4. Apply inverse Fourier transform to calculate displacement time history waveform

Additionally, the displacement data of the linear motor active mass damper was processed as follows.

1. Apply Fourier transform

2. Apply BPF to remove the influence of high and low frequency noise

3. Apply inverse Fourier transform to calculate displacement time history waveform

The measurement accuracy for the displacement is evaluated by using the ratio of the maximum value to the reference. The displacement data of the linear motor active mass damper (D) is used as a reference. First, the positive and negative maximum values of the time history waveform were extracted as shown in Figure 7. Second, the ratio of each maximum values to those of the reference were determined. Third, the mean value of the ratios for 10 waves was calculated. Then, the mean and standard deviations of the 10 sets of experiments were calculated.

The average of the maximum ratio values is no less than 0.9986 and no more than 1.0409 in all cases. Also, the standard deviation show low values, no more than 0.002757 . These results indicate that the MEMS acceleration sensor has a high measurement accuracy for displacement. Furthermore, no particular difference is observed between the test cases with X direction and the Y direction. This result again indicates that there is no sensitivity of the measurement accuracy to excitation direction.

Figure 8 shows the relationship between frequency and average displacement maximum value ratio. As is seen in the results of the measurement accuracy of acceleration, the standard deviation tends to increase at low frequencies. This tendency is more significant in the results of the measurement accuracy for the displacement. Figure 9 shows the relationship between amplitude and average displacement maximum value ratio. The accuracy and the variation tend to increase at large amplitudes. This tendency is more remarkable than that of the acceleration results, although 
it should be noted that the variation is very small even in the case of large amplitude. Given these results, it has been confirmed that the MEMS acceleration sensor can accurately measure the acceleration even for large amplitude vibrations of $1 \mathrm{~m}$ and vibration periods of 10 seconds.

Therefore, it is concluded that the MEMS acceleration sensor has sufficient measurement accuracy as a sensor used for monitoring systems for both accelerations and displacements. The MEMS acceleration sensor can be applied to buildings in which long period and large amplitude vibrations occur.

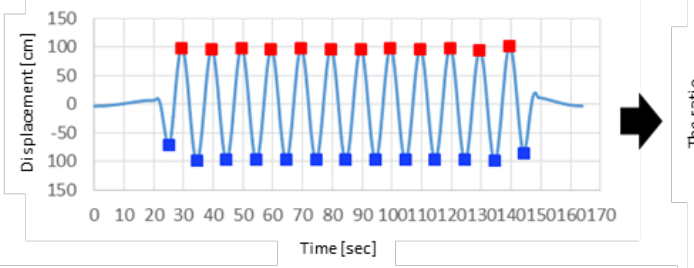

Exracting the positive and negative maximum values

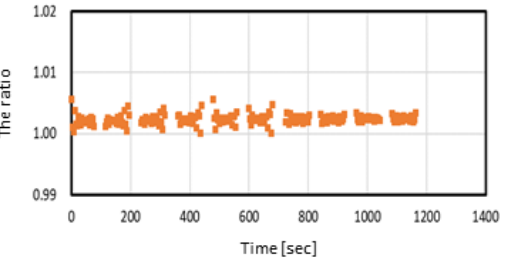

Comparing to the reference

Figure 7: The evaluation method for displacement

Table 4: Averages and standard deviations of the ratios of the maximum displacement values

\begin{tabular}{|c|c|c|c|c|c|c|c|c|c|c|c|c|c|c|c|c|c|}
\hline \multirow{2}{*}{$\begin{array}{c}\text { Case } \\
\text { No. }\end{array}$} & \multirow{2}{*}{$\begin{array}{c}\text { Amplitude } \\
{[\mathrm{cm}]}\end{array}$} & \multirow{2}{*}{$\begin{array}{c}\text { Freaquency } \\
{[\mathrm{Hz}]}\end{array}$} & \multirow{2}{*}{ Direction } & \multicolumn{2}{|c|}{ id101 } & \multicolumn{2}{|c|}{ id102 } & \multicolumn{2}{|c|}{ id 103} & \multicolumn{2}{|c|}{ SU501-1 } & \multicolumn{2}{|c|}{ SU202-2 } & \multicolumn{2}{|c|}{ SU202-3 } & \multicolumn{2}{|c|}{$\mathrm{K} 1, \mathrm{~K} 2$} \\
\hline & & & & mean & Deviation & mean & Deviation & mean & Deviation & mean & Deviation & mean & Deviation & mean & Deviation & mean & Deviation \\
\hline 1 & 100 & 0.10 & $x$ & 1.0190 & $1.857 \mathrm{E}-03$ & 1.0170 & $1.782 \mathrm{E}-03$ & 1.0189 & $1.779 \mathrm{E}-03$ & 1.0263 & $1.931 \mathrm{E}-03$ & 1.0158 & $1.892 \mathrm{E}-03$ & 1.0406 & $1.980 \mathrm{E}-03$ & 1.0300 & $1.785 \mathrm{E}-03$ \\
\hline 2 & 100 & & $\mathrm{Y}$ & 1.0024 & $1.679 \mathrm{E}-03$ & 1.0034 & $9.165 \mathrm{E}-04$ & 1.0046 & $9.311 \mathrm{E}-04$ & 1.0409 & $1.285 \mathrm{E}-03$ & 1.0124 & $1.199 \mathrm{E}-03$ & 1.0214 & $1.285 \mathrm{E}-03$ & 1.0270 & $5 \mathrm{E}-03$ \\
\hline 3 & & & $\frac{1}{x}$ & 1.0168 & $2.757 \mathrm{E}-03$ & 1.0151 & $2.323 \mathrm{E}-03$ & 1.0170 & $4 \mathrm{E}-03$ & 1.0244 & $1.455 \mathrm{E}-03$ & 1.0140 & $1.395 \mathrm{E}-03$ & 1.0387 & $1.575 \mathrm{E}-03$ & 1.0281 & $2.522 \mathrm{E}-03$ \\
\hline 4 & & & $\bar{Y}$ & & & & & & & 1.0396 & & & & 1.0201 & & 1.0257 & $8.389 \mathrm{E}-04$ \\
\hline 5 & & & $\bar{x}$ & 1.0158 & $7.968 \mathrm{E}-04$ & 1.0139 & $7.458 \mathrm{E}-04$ & 1.0158 & $7.564 \mathrm{E}-04$ & 1.0227 & $3.143 \mathrm{E}-04$ & 1.0124 & $36 \mathrm{E}-04$ & 1.0370 & $3.356 \mathrm{E}-04$ & 1.0265 & $7.381 \mathrm{E}-04$ \\
\hline 6 & & & $\hat{Y}$ & 1.0002 & & 1.0017 & & 1.0028 & & 1.0384 & & & & 1.0190 & & 1.0246 & $4.833 \mathrm{E}-04$ \\
\hline 7 & 60 & & $x$ & 1.0155 & & 1.0137 & & 1.0156 & & 1.0226 & & 1.0 & & 1.0369 & & 1.0 & $\frac{2 E-03}{2 E}$ \\
\hline 8 & 60 & & $\bar{Y}$ & 0.9995 & & 1.0009 & & 1.0020 & & 1.0378 & & & & 1.01 & & 1.02 & $8.879 \mathrm{E}-04$ \\
\hline 9 & 60 & & $x$ & & & 1.01 & & 1.0 & & 1.0213 & & & -04 & 1.03 & -04 & 1.0251 & $1.399 \mathrm{E}-03$ \\
\hline 10 & 60 & 0.25 & $\bar{Y}$ & 0.9998 & EE-03 & 1.0013 & $1.202 \mathrm{E}-03$ & 1.0024 & $2 \mathrm{E}-03$ & 1.0374 & & 1.0 & -04 & 1.0180 & & 1.0236 & \\
\hline 11 & 40 & & $x$ & 1.0137 & & 1.01 & & 1.0 & & 1.02 & & 1.0 & & 1.0 & & 1.0 & $2.195 \mathrm{E}-03$ \\
\hline 12 & 40 & & $\bar{Y}$ & 0.9986 & & 1.0000 & $\mathrm{E}-03$ & & & & & & $4 \mathrm{E}-04$ & 1.0 & $2.330 \mathrm{E}-04$ & 1.0235 & \\
\hline 13 & 40 & 0.25 & $x$ & 1.0135 & $1.120 \mathrm{E}-03$ & 1.0116 & $1.107 \mathrm{E}-03$ & 1.0135 & $1.112 \mathrm{E}-03$ & 1.0204 & $3.849 \mathrm{E}-04$ & 1.0102 & $4.187 \mathrm{E}-04$ & 1.0347 & $4.237 \mathrm{E}-04$ & 1.0243 & $1.124 \mathrm{E}-03$ \\
\hline 14 & 40 & 0.25 & & 0.9990 & $9.684 \mathrm{E}-04$ & 1.0004 & $9.493 \mathrm{E}-04$ & 1.0015 & $9.379 \mathrm{E}-04$ & 1.0372 & $2.359 \mathrm{E}-04$ & 1.0089 & $2.599 \mathrm{E}-04$ & 1.0178 & $2.608 \mathrm{E}-04$ & 1.0234 & $9.546 \mathrm{E}-04$ \\
\hline
\end{tabular}

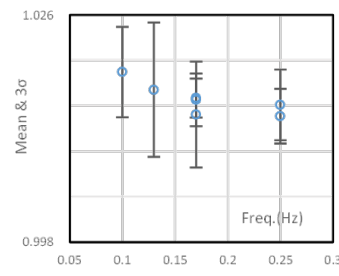

a) id 101

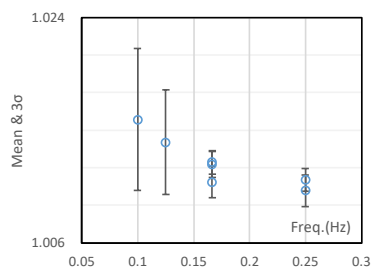

b) SU202-2

Figure 8: The relationship between the frequency and the measurement accuracy (Direction X)

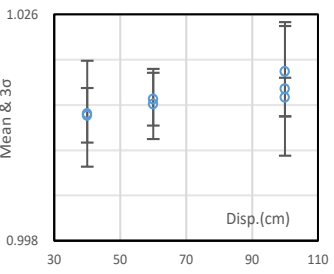

a) id 101

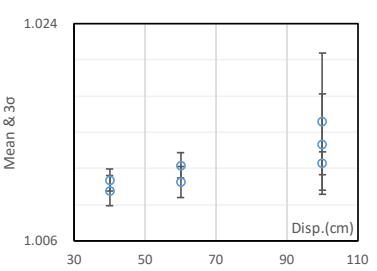

b) SU202-2
Figure 9: The relationship between the amplitude and the measurement accuracy (Direction X)

\section{Measurements accuracy for simulated earthquake motion}

Similar to the previous assessments, BPF was applied to remove the influence of high and low frequency noise for the evaluation of measurement accuracy for simulated earthquake motions. The specifications of the bandpass filter are also the same (figure 3) those of the accuracy verification for under 6 seconds. The displacement data was calculated by second-order integration of the acceleration data.

Evaluation of measurement accuracy for displacement was performed as follows;

1. Apply Fourier transform 
2. Apply BPF to remove the influence of high and low frequency noise

3. Convert to displacement data by second-order integration

4. Apply inverse Fourier transform to calculate displacement time history waveform

The measurement accuracy is evaluated for simulated earthquake response by using the ratio of the maximum value to the reference. The ratio of the Fourier spectrum maximum value to the reference is calculated to evaluate measurement accuracy for acceleration. The ratio of the displacement maximum value of the time history data to the reference is calculated to evaluate measurement accuracy for displacement. Reference servo accelerometer was used as the reference for acceleration evaluation, and the displacement data of linear motor active mass damper was used as the reference for displacement evaluation.

The displacement maximum values in each test case are shown in Table 5. The maximum ratio of acceleration is no less than 0.986 and no more than 1.012. The maximum ratio of displacement is no more than 1.0379. Therefore, the MEMS acceleration sensor appears to have high measurement accuracy for both acceleration and displacement for simulated earthquake response. Note that the maximum deviation of test case 16-1 is larger than the value mentioned above. However, it should be excluded from consideration because of the lack of measurement in the latter half of the data.

Table 5: The ratios of the maximum values

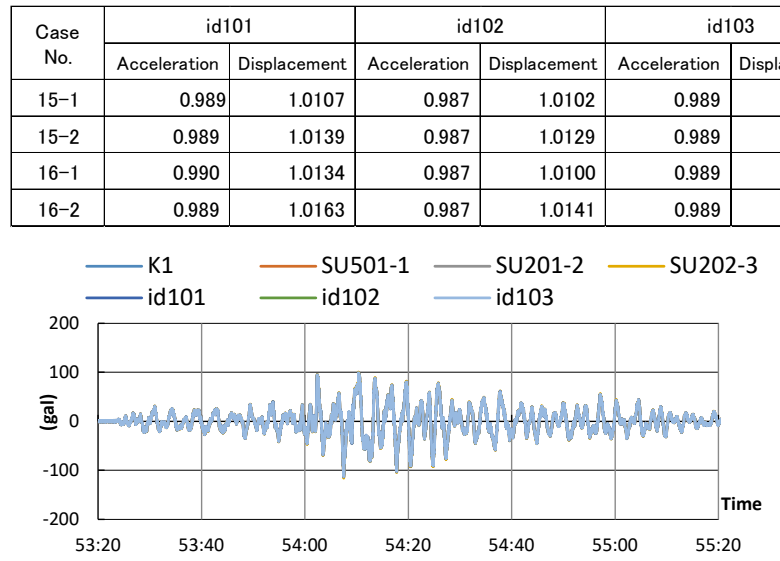

Figure 10: Comparison of acceleration wave (Case No.15-2)

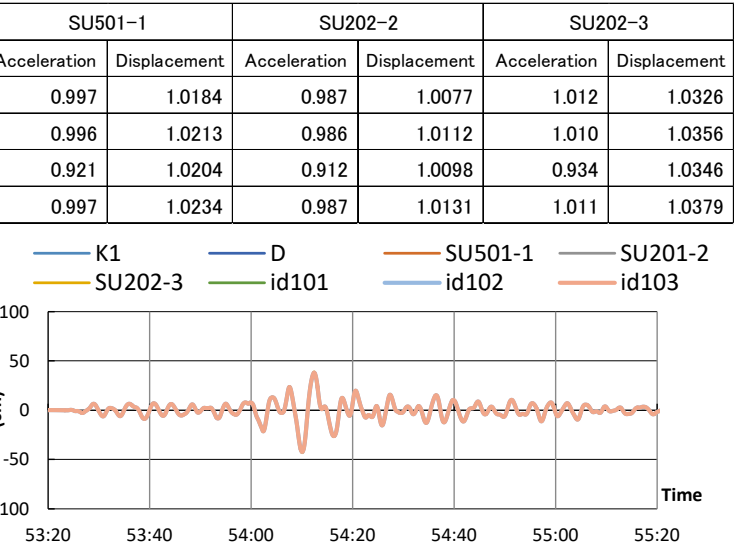

Figure 11: Comparison of displacement wave (Case No.15-2)

\section{Conclusions}

The evaluation of measurement accuracy of MEMS sensor for long period and large amplitude vibrations is concluded as follows;

- The results of the experiments indicate that MEMS acceleration sensors show great agreement in terms of measurement accuracy compared to reference servo type acceleration sensors for acceleration and displacement.

- While as the period becomes longer and the amplitude becomes larger, the variation in measurement accuracy tends to increase. It is possible to accurately measure vibration amplitudes as large as $1 \mathrm{~m}$ and long period vibrations of 10 seconds. 
- It is possible to measure vibrations that simulates an earthquake response accurately.

- The MEMS acceleration sensor has sufficient measurement accuracy for use in monitoring systems.

\section{References}

[1] Nikken Sekkei Structural Monitoring System, Retrieved August 23, 2020, from https://www.nikken.co.jp/ja/expertise/structural_engineering/nikken_sekkei_structural_monitori ng_system.html

[2] T. Ishizaki, H. Imaeda, H. Harada, T. Shinohara, Verification of a Damage Estimation System with a Full Scale Shaking Table Test. Proceedings of The 7th Asia-Pacific Workshop on Structural Health Monitoring, pp.381-388

[3] IHI Infrastructure Systems Co.,Ltd. website, Retrieved August 23, 2020, from https://www.ihi.co.jp/iis/news/2018/180618.html

[4] T. Yaguchi, Y. Nitta, A. Nishitani “Benchmark Test of MEMS Accelerometer for Structural Monitoring" (in Japanese), Summaries of technical papers of annual meeting of AIJ (2007), pp. 47-48

[5] M. Takaki, Y. Yamamoto, Y. Uchiyama "The performance test of the MEMS acceleration sensor" (in Japanese), Summaries of technical papers of annual meeting of AIJ (2010), pp. 831-832

[6] T. Matsushita, K. Yoshida, H. Nishii, K. Goto “Technology Development of Structure Health Monitoring Aiming at Improvement of Resilience Part3 Shaking experiments" (in Japanese), Summaries of technical papers of annual meeting of AIJ (2015), pp. 933-934 